\title{
Victimization and substance use disorders in a national sample of heterosexual and sexual minority women and men
}

\author{
Tonda Hughes', Sean Esteban McCabe ${ }^{2}$, Sharon C. Wilsnack ${ }^{3}$, Brady T. West ${ }^{4}$ \& Carol J. Boyd ${ }^{5}$ \\ College of Nursing (MC 802), University of Illinois at Chicago, Chicago, IL, USA,' Substance Abuse Research Center, Institute for Research on Women and Gender, \\ University of Michigan, Ann Arbor, MI, USA, ${ }^{2}$ Department of Clinical Neuroscience, University of North Dakota School of Medicine and Health Sciences, Grand \\ Forks, ND, USA, ${ }^{3}$ Center for Statistical Consultation and Research, University of Michigan, Ann Arbor, Michigan, USA ${ }^{4}$ and Institute for Research on Women and \\ Gender, School of Nursing and Women's Studies Department, University of Michigan, Ann Arbor, MI, USA ${ }^{5}$
}

\section{ABSTRACT}

Context There is consensus in the research literature that substance use disparities exist among sexual minority women and men; however, few studies have examined risk factors that may contribute to these disparities. Aims To compare reports of life-time victimization experiences in a US national sample of adult heterosexual and sexual minority women and men and to examine the relationships between victimization experiences and past-year substance use disorders. Design, participants, measurements The secondary data analyses used 2004-05 (wave 2) National Epidemiologic Survey on Alcohol and Related Conditions (NESARC) data collected in structured diagnostic face-to-face interviews in the United States. Substance use disorders (SUDs) were defined according to DSM-IV criteria and included past-year alcohol abuse, alcohol dependence, drug abuse and drug dependence. The sample consisted of 34653 adults aged 20 years and older; approximately $2 \%$ of the respondents self-identified as sexual minority (lesbian, gay or bisexual). Findings Results showed strong associations between victimization and any past-year SUDs and confirmed findings from several previous studies indicating that, compared with heterosexuals, sexual minority women and men are at heightened risk for life-time victimization. However, prevalence of the seven victimization experiences and the degree of association between individual victimization experiences and SUDs varied substantially across sexual minority subgroups. The childhood victimization variables—especially childhood neglect-showed the strongest and most consistent associations with SUDs. Odds of SUDs were generally higher among both female and male respondents, regardless of sexual identity, who reported multiple (two or more) victimization experiences than among those who reported no life-time victimization, suggesting a possible cumulative effect of multiple victimization experiences. Conclusions Higher rates of life-time victimization, particularly victimization experienced in childhood, may help to explain higher rates of substance use disorders among sexual minorities. However, more research is needed to understand better the complex relationships among sexual orientation, victimization and substance use.

Keywords DSM-IV substance use disorders, epidemiology, sexual identity, sexual orientation, victimization.

Correspondence to: Tonda Hughes, College of Nursing (MC 802), University of Illinois at Chicago, 845 S. Damen Avenue, Room 956, Chicago, IL 60612-7350, USA. E-mail: thughes@uic.edu

Submitted 18 September 2009; initial review completed 23 December 2009; final version accepted 21 May 2009

\section{INTRODUCTION}

Growing evidence points to heightened risk of substance use and substance use disorders (SUDs) among sexual minority (lesbian, gay, bisexual) women and men [1-6]. Drabble and colleagues [2] found that lesbians were 11 times as likely as heterosexual women to meet criteria for alcohol dependence and eight times as likely to have sought help for alcohol-related problems. Similarly, Wilsnack et al. [6] found that lesbians were more than twice as likely as heterosexual women to report past concerns about their drinking, and nearly five times as likely to have received help for alcohol-related problems. In recent analyses from the National Epidemiologic Survey on Alcohol and Related Conditions (NESARC), gay men had significantly higher odds than heterosexual men of 
past-year marijuana use, other drug use, alcohol dependence and drug dependence [3]. One compelling explanation for this heightened risk is sexual minorities' exposure to multiple chronic stressors that may have cumulative effects. Such exposure often begins with early victimization, especially sexual and physical abuse [7-10], and continues with revictimization in adulthood [11-14].

Childhood sexual abuse (CSA) and childhood physical abuse (CPA) are major early life stressors that have been linked consistently with adverse mental health consequences, including substance use and SUDs [15-20]. However, risks of adverse consequences vary considerably among individuals [21,22], and many questions remain about which population subgroups are at greatest risk. Ample research shows that sexual minorities are more likely than heterosexuals to report both childhood victimization [9-11,13,23-25] and SUDs [2,4,26]. Differences in childhood victimization prevalence aside, the relative risk for SUDs associated with victimization may differ because of sexual orientation-related factors. For example, given that stigma, shame and secrecy often surround both CSA and early recognition of same-gender attraction, coping with CSA may be particularly burdensome for sexual minorities $[27,28]$.

Individuals victimized in childhood are much more likely to be revictimized [29]. In one of the few studies of revictimization among sexual minorities, Heidt et al. [12] found that nearly $63 \%$ of study participants reported lifetime sexual assault. Those who were revictimized scored significantly higher on measures of psychological distress than did non-victims or victims of CSA or adult sexual assault (ASA) only, suggesting a cumulative effect of revictimization. Efforts to assess effects of combined childhood and adult victimization have demonstrated the enduring nature of early trauma and the impact of additional life-time stressors [30-34]. Despite evidence of the impact of specific traumatic experiences on mental health, few researchers have examined the combined effects of such stressors across the life-span; even fewer have focused upon sexual minorities. Such information may provide important clues to understanding substance use and mental health disparities in this population.

We tested two hypotheses related to victimization and SUDs: first, that sexual minority women and men will report more life-time victimization experiences than heterosexual women and men; and secondly, that victimization will be associated positively with past-year SUDs. Although there is insufficient information to derive explicit hypotheses, it is plausible that sexual minorityspecific stressors (e.g. anti-gay bias and discrimination) may compound the impact of victimization. Therefore, we also explored interactions between individual victimization experiences and sexual identity in models predicting SUDs. We tested these hypotheses using data from the
2004-05 wave 2 National Epidemiologic Survey on Alcohol and Related Conditions (NESARC).

\section{METHODS}

\section{Study design}

The target population was the civilian, noninstitutionalized population of the United States, aged 20 years and older. Our analyses focus upon a representative sample from this population, first interviewed in 200102. Data were collected in face-to-face interviews conducted in respondents' homes. The NESARC study design includes stratification and clustering of the target population. Sampling weights were computed for wave 2 respondents to offset unequal probabilities of selection, differential non-response and post-stratification of the population. Response rates were $81.0 \%$ for wave 1 and $86.7 \%$ for wave 2 , a cumulative response rate of $70.2 \%$ [35-37]. The University of Michigan Institutional Review Board approved the current study.

\section{Measures}

SUDs were assessed using the Alcohol Use Disorders and Associated Disabilities Interview Schedule DSM-IV (AUDADIS-IV) symptom questions to operationalize DSM-IV abuse and dependence for 10 substances (alcohol, marijuana, cocaine, hallucinogens, inhalants, heroin, sedatives, tranquilizers, pain medications and stimulants). A diagnosis of past-year substance abuse requires absence of a diagnosis of dependence and presence of at least one of four DSM-IV abuse criteria in the past 12 months. A dependence diagnosis is based on the presence of at least three of seven DSM-IV dependence criteria in the preceding 12 months. Reliability and validity of SUD diagnoses have been established in numerous psychometric studies [38-48].

\section{Life-time victimization experiences}

CSA and ASA were derived from the question: 'Were you ever sexually assaulted, molested or raped or did you ever experience unwanted sexual activity?'. Follow-up questions asked about age at the first and most recent experience. Experiences that occurred (i) prior to age 18 were considered CSA and (ii) those after age 18, ASA. (iii) CPA was defined based on the question: 'Before you were 18 years old, were you physically attacked or badly beaten up or injured by either of your parents or any other people who raised you?'. (iv) Childhood neglect was assessed by asking: 'Before you were 18 years old, were you seriously neglected by either of your parents or any other people who raised you?'. (v) Partner violence was assessed by asking: 'Were you ever physically attacked or badly 
beaten up by your spouse or romantic partner?'. (vi) A similar question asked about non-partner violence: 'Were you ever physically attacked or badly beaten up or injured by someone else?'. (vii) A final question about assault with a weapon asked: 'Were you ever mugged, held up or threatened with a weapon?'.

\section{Demographic and background characteristics}

Sexual identity was assessed by asking: 'Which of the categories on the card best describes you? (i) heterosexual (straight) (ii) gay or lesbian (iii) bisexual, or (iv) not sure?'. Other demographic characteristics included age, sex, race/ethnicity, educational level and employment status [19,49-54]. In the multivariate analyses we also controlled for history of alcohol or other drug problems in the home (lived with a parent or other adult who had problems with alcohol or drugs when growing up); age of drinking onset (age first started drinking, not counting small tastes or sips of alcohol); age of first sexual intercourse; and PTSD (DSM-IV life-time diagnosis assessed by the AUDADIS-IV symptom questions, consistent with previous research [37]).

\section{Data analysis}

We used specialized variance estimation techniques (e.g. Taylor series linearization) and procedures for analysis of complex sample survey data provided in the SUDAAN software package (version 10.0.1) to accommodate the complex sample design. We computed weighted estimates of parameters describing the demographic distribution of the target population. We compared the prevalence of each of the seven victimization experiences and SUDs across four sexual identity subgroups (heterosexual, lesbian/gay, bisexual, not sure) separately for women and men. We computed prevalence estimates and designbased confidence intervals of past-year SUDs crossclassified by past victimization experiences and current sexual identity.

We conducted multivariate analyses to examine sexual identity and victimization (and their interactions) as predictors of past-year SUDs. Design-based logistic regression models were fitted separately for women and men to the four SUD outcome variables. Independent variables were binary indicators of sexual identity and the seven victimization experiences. To explore the potential moderation effects of sexual identity by victimization, interaction terms between the individual victimization experiences and sexual identity were included in the models and tested for significance one at a time [55].

\section{RESULTS}

\section{Demographic characteristics}

As shown in Table 1 , the sample $(n=34653)$ represented a population that was approximately $52 \%$ female, $71 \%$ white, $11 \%$ black, $4 \%$ Asian, $12 \%$ Hispanic and $2 \%$ Native American; about $2 \%$ of respondents $(n=577)$ identified as lesbian, gay or bisexual. The sexual minority subsample (data not shown) closely resembled the overall sample.

\section{Past-year substance use disorders and life-time victimization among women}

Table 2 (left) summarizes the weighted prevalence estimates for any past-year SUD and the individual victimization experiences among women. Those who identified as

Table 1 Weighted estimates of demographic characteristics of NESARC wave 2 target population $(n=34653)$.

\begin{tabular}{|c|c|c|}
\hline & $n^{a}$ & $\%(S E)^{b}$ \\
\hline \multicolumn{3}{|l|}{ Sex } \\
\hline Male & 14564 & $47.92(0.34)$ \\
\hline Female & 20089 & $52.08(0.34)$ \\
\hline \multicolumn{3}{|l|}{ Age (years) } \\
\hline 20-24 & 2183 & $7.61(0.23)$ \\
\hline $25-44$ & 13333 & $38.47(0.40)$ \\
\hline $45-64$ & 11960 & $34.61(0.32)$ \\
\hline 65 and older & 7177 & $19.31(0.34)$ \\
\hline \multicolumn{3}{|l|}{ Race/ethnicity } \\
\hline White & 20161 & $70.91(1.54)$ \\
\hline Black & 6587 & $11.05(0.66)$ \\
\hline Native American & 578 & $2.19(0.18)$ \\
\hline Asian or Pacific Islander & 968 & $4.27(0.52)$ \\
\hline Hispanic & 6359 & 11.58 (1.19) \\
\hline \multicolumn{3}{|l|}{ Education level } \\
\hline Less than high school & 5514 & $14.02(0.45)$ \\
\hline Completed high school & 9452 & $27.48(0.53)$ \\
\hline More than high school & 19687 & $58.50(0.63)$ \\
\hline \multicolumn{3}{|l|}{ Employment status } \\
\hline $\begin{array}{l}\text { Working full-time (+35 hours } \\
\text { a week) }\end{array}$ & 17833 & $53.00(0.40)$ \\
\hline $\begin{array}{l}\text { Working part-time }(<35 \text { hours } \\
\text { a week) }\end{array}$ & 3675 & $10.90(0.20)$ \\
\hline Not working & 13145 & $36.10(0.43)$ \\
\hline \multicolumn{3}{|l|}{ Relationship status } \\
\hline Married/cohabitating & 18866 & $63.79(0.48)$ \\
\hline Widowed/divorced/separated & 9149 & $18.86(0.26)$ \\
\hline Never married & 6638 & $17.35(0.45)$ \\
\hline \multicolumn{3}{|l|}{ Sexual identity } \\
\hline Heterosexual & 33598 & $98.07(0.10)$ \\
\hline Lesbian/gay & 335 & $0.85(0.07)$ \\
\hline Bisexual & 242 & $0.62(0.05)$ \\
\hline Unsure & 170 & $0.46(0.04)$ \\
\hline
\end{tabular}

aBased on unweighted data. ${ }^{b}$ Based on weighted data. NESARC: National Epidemiologic Survey on Alcohol and Related Conditions; SE: standard error. 


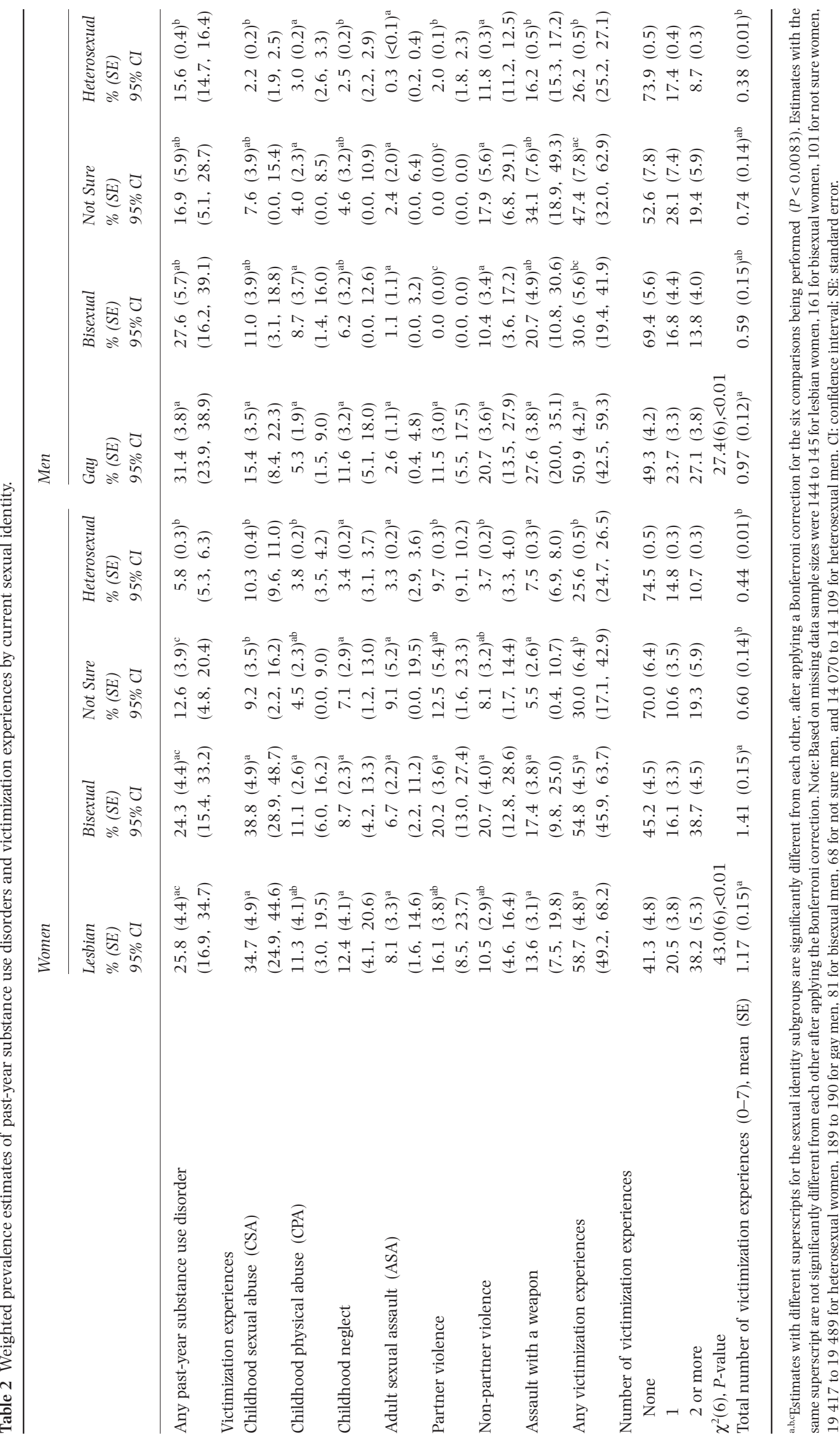


lesbian or bisexual were about twice as likely as heterosexual women to meet criteria for any past-year SUD and about twice as likely as heterosexual women and women who were unsure about their sexual identity to report any victimization experience. Bisexual women were more likely than heterosexual women to report CSA, CPA, partner violence and non-partner violence. Lesbians differed from heterosexual women only in reports of CSA. Unsure women did not differ from heterosexual women on any victimization experiences. Lesbians and bisexual women reported more victimization experiences than did heterosexual women or unsure women.

Table 3 shows the weighted prevalence estimates of any SUD based on each of the victimization experiences. Whereas findings for heterosexual women fitted the expected pattern of greater prevalence of SUDs among those who reported victimization, results were much less consistent among sexual minority and unsure women. CPA, childhood neglect and partner violence appeared to have the greatest impact on SUDs among lesbians. For example, lesbians who reported CPA were more than twice as likely as those who did not to meet criteria for any SUD. Among bisexual women, CSA, partner violence and assault with a weapon were associated with greater SUD prevalence. Several victimization experiences showed an unexpected relationship with SUDs: women who reported the experience were less likely than those who did not report it to meet criteria for SUDs (e.g. lesbians who reported ASA and non-partner violence and unsure women who reported CSA, CPA, partner violence and non-partner violence).

Past-year substance use disorders and life-time victimization among men

There were fewer differences in SUDs and victimization experiences based on sexual identity among men than among women, and these were mainly in comparisons of gay and heterosexual men. As shown in Table 2, gay men were twice as likely as heterosexual men to meet criteria for SUDs and about twice as likely to report any victimization experience as heterosexual or bisexual men. Unsure men were more likely than heterosexual men to report any victimization experiences.

CSA was much more prevalent among gay men than heterosexual men. Gay men were also more likely than heterosexual men to report childhood neglect, partner violence and assault with a weapon. With the exception of partner violence, bisexual and unsure men did not differ from gay or heterosexual men on any individual victimization experiences (no bisexual or unsure men reported partner violence). Gay men also reported a greater number of victimization experiences than heterosexual men.
As with women, associations between SUDs and victimization experiences were in the expected direction for heterosexual men, but less so for gay and unsure men (Table 3). Among these two groups, most of the victimization experiences appeared to confer little or no greater risk of SUDs - or to have the opposite effect. Among gay men, only childhood neglect showed a clear and strong relationship with SUDs in the expected direction. Bisexual men who reported CSA, childhood neglect, non-partner violence and assault with a weapon were more than twice as likely as those who did not report these experiences to meet criteria for any SUD.

\section{Multivariate associations among sexual identity, life-time victimization and SUDs: women}

Table 4 summarizes results of logistic regression analyses examining the relationship between sexual identity and victimization and past-year SUDs. As shown at the top of the table, lesbians had significantly greater odds than heterosexual women of alcohol abuse and drug dependence. The remainder of the table summarizes results of logistic regression models in which no significant interactions were found. None of the individual victimization experiences were associated significantly with alcohol abuse or drug dependence. However, odds of drug abuse were higher among women, regardless of sexual identity, who had experienced CSA, CPA or ASA. Women who reported two or more victimization experiences had higher odds of alcohol dependence [adjusted odds ratio $(\mathrm{AOR})=2.1$, confidence interval $(\mathrm{CI})=1.4-3.0]$, drug abuse (AOR $=$ 3.5, $\mathrm{CI}=2.1-5.9)$ and drug dependence $(\mathrm{AOR}=4.3$, $\mathrm{CI}=1.8-10.3)$ than women who reported none (data not shown).

We found a significant interaction between sexual identity and childhood neglect in predicting alcohol dependence (design-based Wald $F_{(2,65)}=3.32, \quad P=$ 0.042). Among women who had not experienced childhood neglect, lesbians had marginally higher odds of alcohol dependence than heterosexual women $[\mathrm{AOR}=2.4, \mathrm{CI}=1.0,5.8$, not significant $(\mathrm{NS})]$. However, among those who reported childhood neglect, lesbians had more than 30 times the odds of alcohol dependence $(\mathrm{AOR}=30.5, \mathrm{CI}=5.2,181.2)$. No other interactions were significant. We found a significant main effect of adult sexual assault; odds of alcohol dependence for women who reported ASA were higher than for women who did not report this experience, regardless of sexual identity $(\mathrm{AOR}=2.4, \mathrm{CI}=1.6,3.7)$.

\section{Multivariate associations among sexual identity, life-time victimization and SUDs: men}

Neither sexual identity nor any of the individual victimization experiences were associated significantly with 


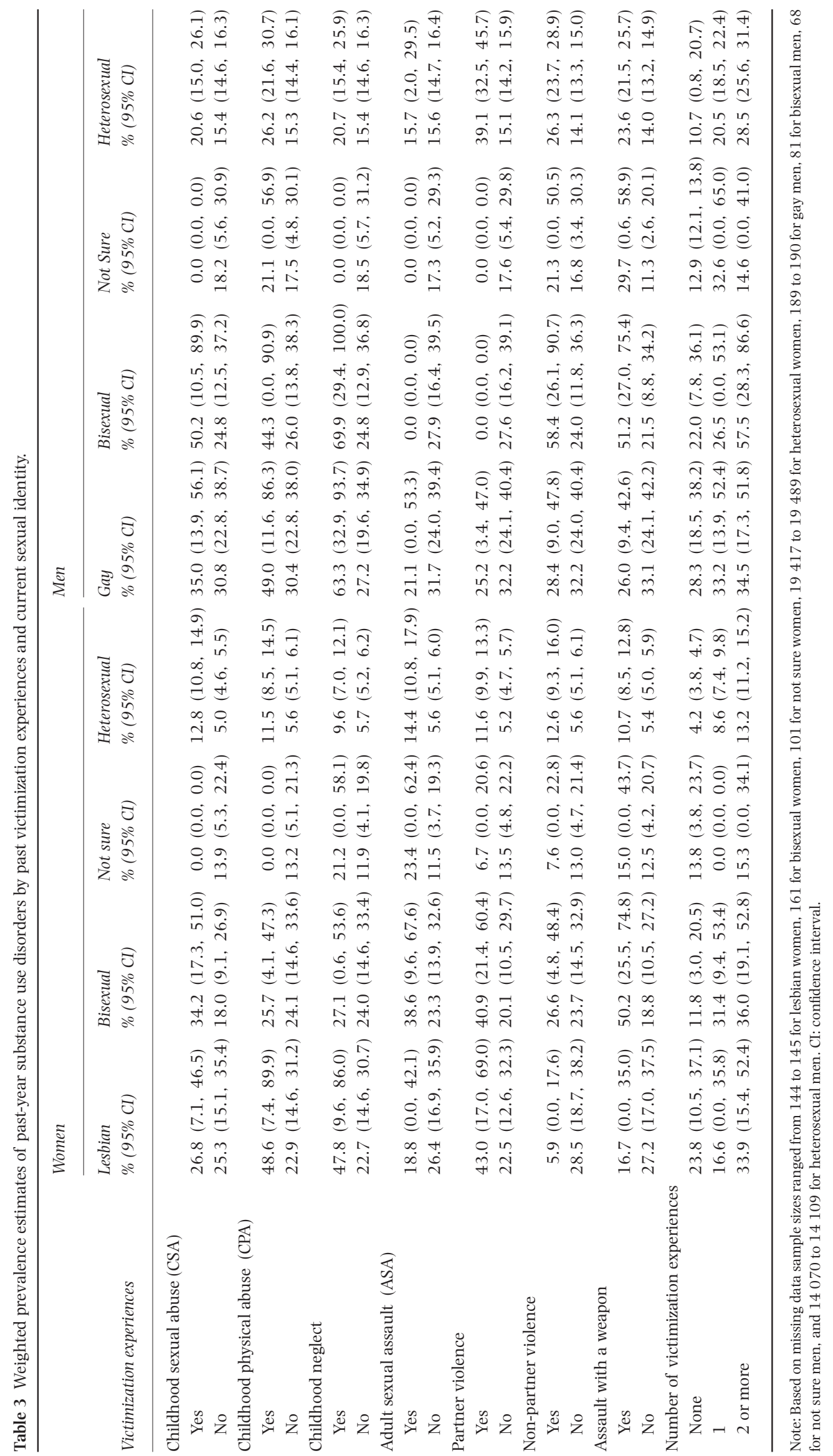


Table 4 Logistic regression: relationships of sexual identity ${ }^{\mathrm{c}}$ and victimization with substance use disorders.

\begin{tabular}{|c|c|c|c|c|c|}
\hline & \multicolumn{3}{|l|}{ Women } & \multicolumn{2}{|l|}{ Men } \\
\hline & $\begin{array}{l}\text { Past-year } \\
\text { alcohol abuse } \\
\text { AOR }(95 \% \text { CI })^{b}\end{array}$ & $\begin{array}{l}\text { Past-year } \\
\text { drug abuse } \\
\text { AOR }(95 \% \text { CI })^{b}\end{array}$ & $\begin{array}{l}\text { Past-year drug } \\
\text { dependence } \\
\text { AOR }(95 \% \text { CI })^{b}\end{array}$ & $\begin{array}{l}\text { Past-year } \\
\text { alcohol abuse } \\
\text { AOR }(95 \% \text { CI })^{b}\end{array}$ & $\begin{array}{l}\text { Past-year } \\
\text { drug abuse } \\
\text { AOR }(95 \% \text { CI })^{b}\end{array}$ \\
\hline \multicolumn{6}{|l|}{ Sexual identity } \\
\hline Heterosexual & Referent & Referent & Referent & Referent & Referent \\
\hline Lesbian/gay & $4.0(2.1-7.6)^{* * *}$ & $2.0(0.4-10.7)$ & $13.4(4.3-42.3)^{* * *}$ & $1.0(0.5-1.9)$ & $6.4(3.2-12.7)^{* * *}$ \\
\hline Bisexual & $0.7(0.3-2.1)$ & $2.0(0.8-4.7)$ & $0.7(0.2-3.5)$ & $0.4(0.1-1.3)$ & $9.3(3.6-23.9)^{* * *}$ \\
\hline \multicolumn{6}{|c|}{ Childhood sexual abuse } \\
\hline No & Referent & Referent & Referent & Referent & Referent \\
\hline Yes & $1.2(0.9-1.7)$ & $2.2(1.3-3.8)^{* *}$ & $2.3(0.9-6.1)$ & $0.8(0.5-1.3)$ & $1.1(0.5-2.2)$ \\
\hline \multicolumn{6}{|c|}{ Childhood physical abuse } \\
\hline No & Referent & Referent & Referent & Referent & Referent \\
\hline Yes & $0.9(0.5-1.5)$ & $2.3(1.1-4.5)^{*}$ & $0.7(0.3-1.9)$ & $0.8(0.5-1.2)$ & $1.3(0.7-2.3)$ \\
\hline \multicolumn{6}{|c|}{ Childhood neglect } \\
\hline No & Referent & Referent & Referent & Referent & Referent \\
\hline Yes & $0.8(0.4-1.4)$ & $0.6(0.3-1.2)$ & $2.0(0.8-5.0)$ & $0.8(0.5-1.3)$ & $0.6(0.3-1.2)$ \\
\hline \multicolumn{6}{|c|}{ Adult sexual assault } \\
\hline No & Referent & Referent & Referent & Referent & Referent \\
\hline Yes & $1.2(0.7-2.0)$ & $3.1(1.5-6.2)^{* *}$ & $2.2(0.8-6.2)$ & $0.5(0.2-1.4)$ & $0.4(0.1-1.7)$ \\
\hline \multicolumn{6}{|l|}{ Partner violence } \\
\hline No & Referent & Referent & Referent & Referent & Referent \\
\hline Yes & $1.2(0.9-1.6)$ & $1.2(0.7-2.1)$ & $1.5(0.7-3.3)$ & $1.3(0.9-2.0)$ & $2.6(1.5-4.5)^{* * *}$ \\
\hline \multicolumn{6}{|c|}{ Non-partner violence } \\
\hline No & Referent & Referent & Referent & Referent & Referent \\
\hline Yes & $0.9(0.5-1.4)$ & $1.1(0.6-2.0)$ & $0.9(0.4-2.0)$ & $1.1(0.9-1.4)$ & $1.5(1.0-2.2)^{*}$ \\
\hline \multicolumn{6}{|c|}{ Assault with a weapon } \\
\hline No & Referent & Referent & Referent & Referent & Referent \\
\hline Yes & $1.1(0.8-1.6)$ & $1.3(0.8-2.4)$ & $1.2(0.5-2.7)$ & $1.1(0.9-1.4)$ & $1.8(1.2-2.5)^{* *}$ \\
\hline
\end{tabular}

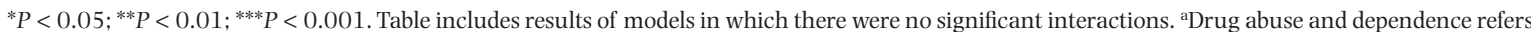
to non-medical use of sedatives, tranquilizers, pain relievers, stimulants, marijuana, cocaine, hallucinogens, inhalants or heroin. ${ }^{\mathrm{b}} \mathrm{AOR}$ indicates odds ratios adjusted for the effects of all aforementioned covariates, including race, age, educational level, employment status, age of drinking onset, age of first sex, life-time post-traumatic stress disorder (PTSD) and history of alcohol/drug problems in the home; estimated odds ratios for these control variables are not shown. ${ }^{\mathrm{c} A n a l y s e s}$ exclude men and women who were unsure about their sexual identity. Sample size for each model ranged from 18202 to 18 288. CI: confidence interval.

alcohol abuse among men, but both gay and bisexual men had significantly higher odds of drug abuse than heterosexual men. Partner violence, non-partner violence and assault with a weapon were each associated with higher odds of drug abuse. Men who reported two or more victimization experiences had significantly higher odds of all four SUD outcomes than those who reported no life-time victimization: alcohol abuse $(\mathrm{AOR}=1.3$, $\mathrm{CI}=1.0-1.7)$, alcohol dependence $(\mathrm{AOR}=1.8, \mathrm{CI}=1.4-$ $2.4)$, drug abuse $(\mathrm{AOR}=3.0, \mathrm{CI}=2.1-4.3)$ or drug dependence $(\mathrm{AOR}=2.6, \mathrm{CI}=1.3-5.1)$ (data not shown).

We found a significant interaction between sexual identity and assault with a weapon in predicting alcohol dependence (design-based Wald $F_{(2,65)}=3.52$, $P=0.035)$. Among those who had not experienced assault with a weapon, odds of alcohol dependence were significantly higher for both gay $(A O R=4.0$, 95\% $\mathrm{CI}=2.2,7.4)$ and bisexual $(\mathrm{AOR}=4.1,95 \% \mathrm{CI}=1.5$, 11.2) men than for heterosexual men. Among those who had experienced assault with a weapon, odds of alcohol dependence did not differ significantly for gay and heterosexual men, but bisexual men had nearly 13 times the odds of heterosexual men $(\mathrm{AOR}=12.7,95 \% \mathrm{CI}=4.9$, 33.1). We also found main effects of partner violence (AOR $=1.8,95 \% \mathrm{CI}=1.1,2.9)$ and non-partner violence (AOR $=1.3,95 \% \mathrm{CI}=1.1,1.7)$ on alcohol dependence; both these experiences increased significantly the odds of this SUD among men, regardless of sexual identity.

The interaction between assault with a weapon and sexual identity was significant in predicting drug dependence (design-based Wald $F_{(2,65)}=4.22, \quad P=0.019$ ). Among those who had not experienced assault with a weapon, gay men had significantly higher odds than heterosexual men of drug dependence (AOR $=5.3,95 \%$ $\mathrm{CI}=1.6,17.6)$, but odds for bisexual and heterosexual men did not differ significantly. Among men who had experienced assault with a weapon, bisexual men had substantially higher odds than heterosexual men 
(AOR $=31.6,95 \% \mathrm{CI}=6.2,162.0)$, but gay and heterosexual men did not differ significantly.

\section{DISCUSSION}

Results support our first hypothesis that, relative to heterosexuals, sexual minority women and men are at heightened risk for life-time victimization. Lesbian and bisexual women were more than twice as likely as heterosexual women to report any life-time victimization. Lesbians, gay men and bisexual women also reported a greater number of victimization experiences. The most pronounced difference between lesbian and heterosexual women was in reports of CSA. Three times as many lesbians $(34.7 \%)$ as heterosexual women (10.3\%) reported this experience. As we [9] and others [7,8,56] have noted, higher rates of CSA may be attributable, in part, to lesbians' greater willingness to acknowledge and report this experience. Research indicates that the majority of lesbians have been in therapy or counseling [57-60]. Through efforts to understand their present difficulties more clearly, women who seek help for mental health concerns - such as relationship issues, depression and anxiety-may be more likely to recall and report CSA. Thus, if lesbians are more willing than heterosexual women to report CSA, some of the differences in prevalence of CSA may be a result of response bias.

Bisexual women were also more likely than heterosexual women to report CSA as well as three other lifetime victimization experiences (CPA, partner violence and non-partner violence). The dearth of data on bisexual women's health and life experiences makes it difficult to speculate about reasons for their high rates of victimization. However, our findings are consistent with other studies showing bisexual women to be at high risk for a variety of mental and physical health problems $[6,61,62]$. To address health disparities in bisexual women, more research with larger samples is greatly needed.

We also found overall higher prevalence of victimization among sexual minority men, but most differences were between gay and heterosexual men. Gay men were more likely to report CSA, childhood neglect, partner violence and assault with a weapon. Again, differences in rates of victimization due to reporting biases versus how much is reflective of actual differences in prevalence is unclear. None the less, findings point to the need for more research on prevalence, risk factors and consequences of victimization among sexual minority men.

Results are consistent with findings from general population samples [34,63] and provide support for our second hypothesis that victimization is associated positively with risk of SUDs. For example, women who reported two or more victimization experiences had two to four times the odds of alcohol dependence, drug abuse and drug dependence as women who reported no victimization. Men who reported two or more victimization experiences had higher odds of all four SUD outcomes, but odds were smaller than those observed in women. These results suggest a possible cumulative effect of multiple victimization, consistent with previous research $[16,30,34,63,64]$.

Associations between victimization and SUDs varied by sexual identity. For example, whereas lesbians who reported CPA, childhood neglect and partner violence had higher rates of past-year SUDs than lesbians who did not report these experiences, CSA, ASA, partner violence and assault with a weapon conferred higher risk of SUDs for bisexual women. Although gay men were significantly more likely than heterosexual men to report four of the seven victimization experiences, these differences did not appear to increase gay men's risk of SUDs. In contrast, although bisexual men were much more similar to heterosexual men in prevalence of victimization experiences, relationships between victimization and SUDs appeared to be stronger in bisexual men than in heterosexual men.

Among women, childhood neglect was the only victimization experience that showed a significant interaction with sexual identity in predicting SUDs. Lesbians who reported childhood neglect had more than 30 times the odds of alcohol dependence as heterosexual women who reported this experience. Gay men were also significantly more likely than heterosexual men to report childhood neglect, and bivariate relationships between childhood neglect and past-year SUDs were very strong for both gay and bisexual men. Researchers have yet to examine the prevalence and impact of childhood neglect on sexual minority women's and men's health, but our findings suggest that this experience may be an important predictor of SUDs in at least some sexual minority subgroups.

Assault with a weapon also showed strong effects on SUDs for some subgroups, particularly bisexual men and men unsure about their sexual identity. Among men who reported this experience bisexual men had nearly 13 times the odds of alcohol dependence and 31 times the odds of drug dependence as heterosexual men.

Collectively, findings from the study suggest that the impact of some victimization experiences on SUDs may be compounded among some sexual minority women and men. Sexual minority youth are believed to be at heightened risk of victimization for several reasons, including their being targeted for abuse/violence by parents, siblings, peers, older children and adults because of antigay stigma and bias [11,65-67]. There is ample evidence that early victimization increases the risk for subsequent revictimization substantially [33]. Given that 
sexual minority youth and adults are more likely than their heterosexual counterparts to use alcohol and other drugs [4,6,68-70], a self-perpetuating cycle may occur in which sexual minorities use substances in part to cope with adverse psychological and interpersonal effects of victimization and this use, in turn, increases risk for further victimization.

Results suggest that efforts to prevent SUDs are likely to benefit from greater understanding of multiple traumatic victimization experiences in the lives of individuals, especially those who identify as lesbian, gay or bisexual. Programs and interventions must go beyond educating youth about the risks of substance use to help youth also recognize and cope with the stressors of childhood physical and sexual abuse, relationship violence and other forms of victimization. Given the high rates of childhood victimization among sexual minority women and men it is important that clinicians who care for sexual minority youth ask routinely about victimization experiences.

Our study has several limitations. Retrospective reporting of childhood experiences is a potential source of bias because respondents may have difficulty recalling and reporting certain events. In addition, because individual victimization experiences were assessed using single questions, these experiences are likely to be under-reported. As with all cross-sectional research, there are uncertainties about the temporal relationships of the major study variables. For example, because questions about sexual identity development milestones (e.g. first recognition of same-sex attraction, first same-sex sexual experience) were not included in the NESARC, we are unable to speculate about whether or to what extent victimization experiences reported by lesbian/gay and bisexual respondents may have been related to their sexual orientation.

There is also the possibility that minority sexual identity and SUDs were under-reported, especially given that data were collected in face-to-face interviews. The prevalence rates of LGB identity in the NESARC are slightly lower than in previous US national probability studies $[2,8,58,71]$ and the substance use rates in the NESARC are generally lower [72]. Replication of these findings using self-administered data collection modes including computer-based approaches, which may produce more accurate reporting of socially sensitive behaviors [73-77], would strengthen confidence in the findings. Finally, some of the prevalence estimates are based on small subsample sizes and should be interpreted cautiously. Despite these limitations, study findings add to the evidence of higher rates of victimization among sexual minority women and men and provide insight into potential reasons for SUD disparities within this population.

\section{Declarations of interest}

None.

\section{Acknowledgements}

The National Epidemiologic Survey on Alcohol and Related Conditions (NESARC) was sponsored by the National Institute on Alcohol Abuse and Alcoholism, National Institutes of Health, United States Department of Health and Human Services, with supplemental support from the National Institute on Drug Abuse. The development of this manuscript was supported by research grants DA023055 and DA007267 from the National Institute on Drug Abuse and AA013328 from the National Institute on Alcohol Abuse and Alcoholism, National Institutes of Health. The content is solely the responsibility of the authors and does not necessarily represent the official views of the National Institute on Drug Abuse, the National Institute on Alcohol Abuse and Alcoholism or the National Institutes of Health.

\section{References}

1. Cochran S. D., Ackerman D., Mays V. M., Ross M. W. Prevalence of non-medical drug use and dependence among homosexually active men and women in the US population. Addiction 2004; 99: 989-98.

2. Drabble L., Midanik L. T., Trocki K. Reports of alcohol consumption and alcohol-related problems among homosexual, bisexual and heterosexual respondents: results from the 2000 National Alcohol Survey. J Stud Alcohol 2005; 66: 111-20.

3. Fergusson D. M., Horwood L. J., Ridder E. M., Beautrais A. L. Sexual orientation and mental health in a birth cohort of young adults. Psychol Med 2005; 35: 971-81.

4. McCabe S. E., Hughes T. L., Bostwick W. B., West B. T., Boyd C. J. Sexual orientation, substance use behaviors and substance dependence in the United States. Addiction 2009; 104: 1333-45.

5. Thiede H., Valleroy L. A., MacKellar D. A., Celentano D. D., Ford W. L., Hagan H. et al. Regional patterns and correlates of substance use among young men who have sex with men in 7 US urban areas. Am J Public Health 2003; 93: 1915-21.

6. Wilsnack S. C., Hughes T. L., Johnson T. P., Bostwick W. B., Szalacha L. A., Benson P. et al. Drinking and drinkingrelated problems among heterosexual and sexual minority women. J Stud Alcohol Drugs 2008; 69: 129-39.

7. Austin S. B., Jun H. J., Jackson B., Spiegelman D., RichEdwards J., Corliss H. L. et al. Disparities in child abuse victimization in lesbian, bisexual, and heterosexual women in the Nurses' Health Study II. J Womens Health (Larchmt) 2008; 17: 597-606.

8. Corliss H. L., Cochran S. D., Mays V. M. Reports of parental maltreatment during childhood in a United States population-based survey of homosexual, bisexual, and heterosexual adults. Child Abuse Negl 2002; 26: 1165-78.

9. Hughes T. L., Johnson T. P., Wilsnack S. C., Szalacha L. A. Childhood risk factors for alcohol abuse and psychological distress among adult lesbians. Child Abuse Negl 2007; 31: 769-89.

10. Tomeo M. E., Templer D. I., Anderson S., Kotler D. Comparative data of childhood and adolescence molestation in heterosexual and homosexual persons. Arch Sex Behav 2001; 30: $535-41$. 
11. Balsam K. F., Rothblum E. D., Beauchaine T. P. Victimization over the life span: a comparison of lesbian, gay, bisexual, and heterosexual siblings. J Consult Clin Psychol 2005; 73: 477-87.

12. Heidt J. M., Marx B. P., Gold S. D. Sexual revictimization among sexual minorities: a preliminary study. J Trauma Stress 2005; 18: 533-40.

13. Hughes T. L., Johnson T., Wilsnack S. C. Sexual assault and alcohol abuse: a comparison of lesbians and heterosexual women. J Subst Abuse 2001; 13: 515-32.

14. Tjaden P., Thoennes N., Allison C. J. Comparing violence over the life span in samples of same-sex and opposite-sex cohabitants. Violence Vict 1999; 14: 413-25.

15. Briere J. The long-term clinical correlates of childhood sexual victimization. Ann NY Acad Sci 1988; 528: 327-34.

16. Dube S. R., Miller J. W., Brown D. W., Giles W. H., Felitti V. J., Dong M. et al. Adverse childhood experiences and the association with ever using alcohol and initiating alcohol use during adolescence. J Adolesc Health 2006; 38: 444.

17. Kendler K. S., Bulik C. M., Silberg J., Hettema J. M., Myers J., Prescott C. A. Childhood sexual abuse and adult psychiatric and substance use disorders in women: an epidemiological and cotwin control analysis. Arch Gen Psychiatry 2000; 57: 953-9.

18. Nelson E. C., Heath A. C., Madden P. A., Cooper M. L., Dinwiddie S. H., Bucholz K. K. et al. Association between selfreported childhood sexual abuse and adverse psychosocial outcomes: results from a twin study. Arch Gen Psychiatry 2002; 59: 139-45.

19. Wilsnack S. C., Vogeltanz N. D., Klassen A. D., Harris T. R. Childhood sexual abuse and women's substance abuse: national survey findings. J Stud Alcohol 1997; 58: 264-71.

20. Wilsnack S. C., Wilsnack R. W., Kristjanson A. F., VogeltanzHolm N. D., Harris T. R. Child sexual abuse and alcohol use among women: setting the stage for risky sexual behavior. In: Koenig L. J., Doll L. S., O'Leary A., Pequegnat W., editors. From Child Sexual Abuse to Adult Sexual Risk: Trauma, Revictimization and Intervention. Washington, DC: American Psychological Association; 2004, p. 181-200.

21. Kendall-Tackett K. A., Williams L. M., Finkelhor D. Impact of sexual abuse on children: a review and synthesis of recent empirical studies. Psychol Bull 1993; 113: 164-80.

22. Widom C. S., Ireland T., Glynn P. J. Alcohol abuse in abused and neglected children followed-up: are they at increased risk? J Stud Alcohol 1995; 56: 207-17.

23. D'Augelli A. R. Lesbian and bisexual female youths aged 14 to 21: developmental challenges and victimization experiences. J Lesbian Stud 2003; 7: 9-29.

24. Fleming J., Mullen P. E., Sibthorpe B., Attewell R., Bammer G. The relationship between childhood sexual abuse and alcohol abuse in women-a case-control study. Addiction 1998; 93: 1787-98.

25. Saewyc E. M., Bearinger L. H., Blum R. W., Resnick M. D. Sexual intercourse, abuse and pregnancy among adolescent women: does sexual orientation make a difference? Fam Plann Perspect 1999; 31: 127-31.

26. Cochran S. D., Mays V. M. Estimating prevalence of mental and substance-using disorders among lesbians and gay men from existing national health data. In: Omoto A., Kurtzman H., editors. Sexual Orientation and Mental Health: Examining Identity and Development in Lesbian, Gay, and Bisexual People. Washington, DC: American Psychology Association; 2005. 143-66.

27. Finkelhor D., Browne A. The traumatic impact of child sexual abuse: a conceptualization. Am J Orthopsychiatry 1985; 55: 530-41.

28. Davis J. L., Petretic-Jackson P. A. The impact of child sexual abuse on adult interpersonal functioning: a review and synthesis of the empirical literature. Aggress Violent Behav 2000; 5: 291-328.

29. Classen C. C., Palesh O. G., Aggarwal R. Sexual revictimization: a review of the empirical literature. Trauma Violence Abuse 2005; 6: 103-29.

30. Dube S. R., Anda R. F., Felitti V. J., Edwards V. J., Croft J. B. Adverse childhood experiences and personal alcohol abuse as an adult. Addict Behav 2002; 27: 713-25.

31. Turner R. J., Lloyd D. A. Lifetime traumas and mental health: the significance of cumulative adversity. J Health Soc Behav 1995; 36: 360-76.

32. Anda R. F., Croft J. B., Felitti V. J., Nordenberg D., Giles W. H., Williamson D. F. et al. Adverse childhood experiences and smoking during adolescence and adulthood. JAMA 1999; 282: $1652-8$.

33. Avison W. R., Turner R. J. Stressful life events and depressive symptoms: disaggregating the effects of acute stressors and chronic strains. J Health Soc Behav 1988; 29: 253-64.

34. Turner R. J., Lloyd D. A. Cumulative adversity and drug dependence in young adults: racial/ethnic contrasts. Addiction 2003; 98: 305-15.

35. Dawson D. A., Goldstein R. B., Grant B. F. Rates and correlates of relapse among individuals in remission from DSM-IV alcohol dependence: a 3-year follow-up. Alcohol Clin Exp Res 2007; 31: 2036-45.

36. Grant B. F., Kaplan K. D. Source and Accuracy Statement for the Wave 2 National Epidemiologic Survey on Alcohol and Related Conditions (NESARC). Rockville, MD: National Institute on Alcohol Abuse and Alcoholism; 2005.

37. Ruan W. J., Goldstein R. B., Chou S. P., Smith S. M., Saha T. D., Pickering R. P. et al. The alcohol use disorder and associated disabilities interview schedule-IV (AUDADIS-IV): reliability of new psychiatric diagnostic modules and risk factors in a general population sample. Drug Alcohol Depend 2008; 92: 27-36.

38. Cottler L. B., Grant B. F., Blaine J., Mavreas V., Pull C., Hasin D. et al. Concordance of DSM-IV alcohol and drug use disorder criteria and diagnoses as measured by AUDADIS-ADR, CIDI and SCAN. Drug Alcohol Depend 1997; 47: 195-205.

39. Grant B. F. DSM-IV, DSM-III-R, and ICD-10 alcohol and drug abuse/harmful use and dependence, United States, 1992: a nosological comparison. Alcohol Clin Exp Res 1996; 20: 1481-8.

40. Grant B. F., Harford T. C., Dawson D. A., Chou P. S., Pickering R. P. The Alcohol Use Disorder and Associated Disabilities Interview schedule (AUDADIS): reliability of alcohol and drug modules in a general population sample. Drug Alcohol Depend 1995; 39: 37-44.

41. Grant B. F., Dawson D. A., Stinson F. S., Chou P. S., Kay W., Pickering R. The Alcohol Use Disorder and Associated Disabilities Interview Schedule-IV (AUDADIS-IV): reliability of alcohol consumption, tobacco use, family history of depression and psychiatric diagnostic modules in a general population sample. Drug Alcohol Depend 2003; 71: 7-16.

42. Hasin D., Li Q., Mccloud S., Endicott J. Agreement between DSM-III, DSM-III-R, DSM-IV and ICD-10 alcohol diagnoses in US community-sample heavy drinkers. Addiction 1996; 91: 1517-27.

43. Hasin D., Carpenter K. M., McCloud S., Smith M., Grant B. F. The alcohol use disorder and associated disabilities 
interview schedule (AUDADIS): reliability of alcohol and drug modules in a clinical sample. Drug Alcohol Depend 1997; 44: 133-41.

44. Hasin D., Grant B. F., Cottler L., Blaine J., Towle L., Ustun B. et al. Nosological comparisons of alcohol and drug diagnoses: a multisite, multi-instrument international study. Drug Alcohol Depend 1997; 47: 217-26.

45. Hasin D., Van Rossem R., McCloud S., Endicott J. Alcohol dependence and abuse diagnoses: validity in community sample heavy drinkers. Alcohol Clin Exp Res 1997; 21: 213-9.

46. Muthén B. O., Grant B., Hasin D. The dimensionality of alcohol abuse and dependence: factor analysis of DSM-III-R and proposed DSM-IV criteria in the 1988 National Health Interview Survey. Addiction 1993; 88: 1079-90.

47. Nelson C. B., Rehm J., Ustun T. B., Grant B., Chatterji S. Factor structures for DSM-IV substance disorder criteria endorsed by alcohol, cannabis, cocaine and opiate users: results from the WHO reliability and validity study. Addiction 1999; 94: 843-55.

48. Pull C. B., Saunders J. B., Mavreas V., Cottler L. B., Grant B. F., Hasin D. S. et al. Concordance between ICD-10 alcohol and drug use disorder criteria and diagnoses as measured by the AUDADIS-ADR, CIDI and SCAN: results of a crossnational study. Drug Alcohol Depend 1997; 47: 207-16.

49. Grant B. F., Stinson F. S., Harford T. C. Age at onset of alcohol use and DSM-IV alcohol abuse and dependence: a 12-year follow-up. J Subst Abuse 2001; 13: 493-504.

50. Hasin D. S., Stinson F. S., Ogburn E., Grant B. F. Prevalence, correlates, disability, and comorbidity of DSM-IV alcohol abuse and dependence in the United States: results from the National Epidemiologic Survey on Alcohol and Related Conditions. Arch Gen Psychiatry 2007; 64: 830-42.

51. Hingson R. W., Heeren T., Winter M. R. Age at drinking onset and alcohol dependence: age at onset, duration, and severity. Arch Pediatr Adolesc Med 2006; 160: 739.

52. Merikangas K. R., Stolar M., Stevens D. E., Goulet J., Preisig M. A., Fenton B. et al. Familial transmission of substance use disorders. Arch Gen Psychiatry 1998; 55: 973.

53. Prescott C. A., Kendler K. S. Age at first drink and risk for alcoholism: a noncausal association. Alcohol Clin Exp Res 1999; 23: 101-7.

54. Rosenbaum E., Kandel D. B. Early onset of adolescent sexual behavior and drug involvement. J Marriage Fam 1990; 52: 783-98.

55. Hosmer D. W., Lemeshow S. Applied Logistic Regression. New York: Wiley-Interscience; 2000.

56. Saewyc E. M., Skay C. L., Pettingell S. L., Reis E. A., Bearinger L., Resnick M. et al. Hazards of stigma: the sexual and physical abuse of gay, lesbian, and bisexual adolescents in the United States and Canada. Child Welfare 2006; 85: 195-213.

57. Bradford J., Ryan C., Rothblum E. D. National lesbian health care survey: implications for mental health care. J Consult Clin Psychol 1994; 62: 228-42.

58. Cochran S. D., Sullivan J. G., Mays V. M. Prevalence of mental disorders, psychological distress, and mental health services use among lesbian, gay, and bisexual adults in the United States. J Consult Clin Psychol 2003; 71: 53-61.

59. Hughes T. L., Haas A. P., Razzano L., Cassidy R., Matthews A. Comparing lesbians' and heterosexual women's mental health: a multi-site survey. J Gay Lesbian Soc Serv 2000; 11: $57-76$.

60. Morgan K. S. Caucasian lesbians' use of psychotherapy: a matter of attitude? Psychol Women Q 2006; 16: 127-30.
61. Bostwick W. B., Boyd C. J., Hughes T. L., McCabe S. E. Dimensions of sexual orientation and the prevalence of mood and anxiety disorders in the United States. Am J Public Health 2010; 100: 468-75.

62. Jorm A. F., Korten A. E., Rodgers B., Jacomb P. A., Christensen $\mathrm{H}$. Sexual orientation and mental health: results from a community survey of young and middle-aged adults. Br J Psychiatry 2002; 180: 423.

63. Pilowsky D. J., Keyes K. M., Hasin D. S. Adverse childhood events and lifetime alcohol dependence. Am J Public Health 2009; 99: 258-63.

64. Briere J., Kaltman S., Green B. L. Accumulated childhood trauma and symptom complexity. J Trauma Stress 2008; 21: 223-6.

65. D’Augelli A. R., Hershberger S. L., Pilkington N. W. Lesbian, gay, and bisexual youth and their families: disclosure of sexual orientation and its consequences. Am J Orthopsychiatry 1998; 68: 361-71.

66. Pilkington N. W., D'Augelli A. R. Victimization of lesbian, gay, and bisexual youth in community settings. J Commun Psychol 2006; 23: 34-56.

67. Ryan C., Huebner D., Diaz R. M., Sanchez J. Family rejection as a predictor of negative health outcomes in white and Latino lesbian, gay, and bisexual young adults. Pediatrics 2009; 123: 346-52.

68. Meyer I. H. Prejudice, social stress, and mental health in lesbian, gay, and bisexual populations: conceptual issues and research evidence. Psychol Bull 2003; 129: 67497.

69. Hughes T. L., Wilsnack S. C., Johnson T. Investigating lesbians' mental health and alcohol use: what is an appropriate comparison group. In: Omoto A. M., Kurtzman H. S., editors. Sexual Orientation and Mental Health: Examining Identity and Development in Lesbian, Gay, and Bisexual People. Contemporary Perspectives on Lesbian, Gay, and Bisexual Psychology. Washington, DC: American Psychology Association; 2006, p. 167.

70. Hughes T. L. Alcohol use and alcohol-related problems among lesbians and gay men. Annu Rev Nurs Res 2005; 23: $283-325$.

71. Laumann E. O., Gagnon J. H., Michael R. T., Michaels S. The Social Organization of Sexuality: Sexual Practices in the United States. Chicago, IL: University of Chicago Press; 2000.

72. Grucza R. A., Abbacchi A. M., Przybeck T. R., Gfroerer J. C. Discrepancies in estimates of prevalence and correlates of substance use and disorders between two national surveys. Addiction 2007; 102: 623-9.

73. Cooley P. C., Miller H. G., Gribble J. N., Turner C. F. Automating telephone surveys: using T-ACASI to obtain data on sensitive topics. Comput Hum Behav 2000; 16: 1-11.

74. Sudman S., Bradburn N. M. Response Effects in Surveys: A Review and Synthesis. Chicago, IL: Aldine; 1974.

75. Turner C. F., Ku L., Rogers S. M., Lindberg L. D., Pleck J. H., Sonenstein F. L. Adolescent sexual behavior, drug use, and violence: increased reporting with computer survey technology. Science 1998; 280: 867-73.

76. Tourangeau R., Smith T. W. Collecting sensitive information with different modes of data collection. In: Couper M., Baker R., Bethlehem J., Clark C., Martin J., Nicholls W., O'Reilly J., editors. Computer Assisted Survey Information Collection. New York: John Wiley \& Sons; 1998, p. 431-54.

77. Tourangeau R., Smith T. W. Asking sensitive questions: the impact of data collection mode, question format, and question context. Public Opin Q 1996; 60: 275. 